\title{
TEMPERATURA E MEIO DE CULTURA MAIS FAVORÁVEIS AO CRESCIMENTO MICELIAL DE UMA LINHAGEM DE LENTINUS STRIGOSUS DE OCORRÊNCIA NA AMAZÔNIA
}

\section{Sales-Campos; M.C.N. de Andrade}

Instituto Nacional de Pesquisas da Amazônia, Coordenação de Pesquisas em Produtos Florestais, Av. André Araújo, 2936, CEP 69060-001, Manaus, AM, Brasil. E-mail: ceci@inpa.gov.br

RESUMO

\begin{abstract}
O objetivo do trabalho foi avaliar o crescimento micelial de uma linhagem de Lentinus strigosus, de ocorrência na Amazônia, em cinco meios de cultura à base de malte, serragem de marupá (Simarouba amara), serragem de pau de balsa (Ochroma piramidale), estipe de pupunheira (Bactris gasipaes Kunth) e bagaço de cana-de-açúcar (Saccharum officinarum), submetidos às temperaturas de 20, 25, 30, 35, 40,45 e $50^{\circ} \mathrm{C}$. O delineamento experimental foi inteiramente casualizado, em esquema fatorial $5 \mathrm{x}$ 7. Cada tratamento constou de quatro repetições, correspondente a uma placa de Petri, totalizando 140 unidades experimentais. Verificou-se que a temperatura de $35^{\circ} \mathrm{C}$ foi a mais favorável para o crescimento micelial de L. strigosus e que o meio à base de estipe de pupunheira foi o mais promissor para o cultivo deste fungo.
\end{abstract}

PALAVRAS-CHAVE: Fungos, micélio, in vitro.

\section{ABSTRACT}

MOSTFAVORABLETEMPERATURE ANDCULTUREMEDIUMFORTHEMYCELIALGROWTH OF A STRAIN OF LENTINUS STRIGOSUS FROM THE AMAZON REGION. The objective of this work was to evaluate the mycelial growth of a strain of Lentinus strigosus occurring in the Amazon region in five culture mediums made on the basis of malt, "marupá" sawdust (Simarouba amara), "pau de balsa" sawdust (Ochroma piramidale), peach palm stipe (Bactris gasipaes Kunth) and crushed sugarcane (Saccharum officinarum), when submitted to different temperatures $(20,25,30,35,40,45$ and $\left.50^{\circ} \mathrm{C}\right)$. The experimental design was totally randomized, in a $5 \times 7$ factorial scheme. Each treatment corresponded to a Petri dish with four repetitions, totaling 140 experimental units. The temperature of $35^{\circ} \mathrm{C}$ was found to be the most favorable for the mycelial growth of L. strigosus, and the medium with peach palm stipe was the most promising for the cultivation of this fungus.

KEY WORDS: Fungi, mycelium, in-vitro.

O aproveitamento de resíduos tem sido considerado uma das grandes temáticas do mundo moderno. Entre as possibilidades de reciclagem desses materiais, o cultivo de cogumelos na Amazônia vem representandouma alternativa eficiente, uma vezque esses fungos possuem uma extraordinária atividade metabólica capaz de converter resíduos madeireiros e agroindustriais em um produto de valor agregado (cogumelo comestível) (SALEs-CAMPOS et al., 2008).

$\mathrm{O}$ cultivo in vitro tem como objetivo identificar as condições ótimas de crescimento do fungo em relação a meios de cultura, temperatura e tempo de incubação (HATVANI, 2001), sendo que o crescimento micelial do fungo, durante um período de tempo, pode ser traduzido por uma curva sigmoidal típica, com várias fases com propriedades fisiológicas típicas (MonTini et al., 2006). Em relação à mensuração do crescimento micelial, esta pode ser feita de diferentes formas, tais como crescimento radial, vigor, velocidade de crescimento e massa do micélio.

Ouso de meio de cultura sólido para avaliação do crescimento defungoséconsideradoadequado, pois, na natureza, os fungos comumente desenvolvem-se em substratos sólidos, tais como resíduos vegetais e animais ou no solo (BonONi et al., 1999). O fungo, em seu metabolismo, secreta exoenzimas que degradam compostos para obtenção de carbono, nitrogênio, enxofre e outros nutrientes (Donini et al., 2005).

Em relação aos fatores ambientais, VARGAS-IsLA; IsHIKAWA (2008) relataram que os testes in vitro disponíveis na literatura para cogumelos são comumente correlacionados com habitats de clima temperado, havendo uma carência de estudos das condições de cultivo para climas tropicais. Portanto, conhecer as condições mais adequadas de temperatura para esses é fundamental, uma vez que, con- 
forme AKINYELE; AdETUYi (2005), a temperatura é um dos principais fatores ambientais que influenciam o crescimento de muitos micro-organismos.

Quanto aos meios de cultivo, devido à grande diversidade existente, conhecer o mais apropriado para uma determinada linhagem fúngica éum modo para aumentar a produtividade, uma vez que, como já relatado por SiLva et al. (2005), o crescimento do micélio influencia a produção de cogumelos e a taxa de formação de primórdios, bem como está diretamente relacionado com a biomassa micelial que é formada durante o crescimento fúngico.

Assim, o presente trabalho teve como objetivo avaliar o efeito da temperatura e do meio de cultura no crescimento micelial de Lentinus strigosus.

Oexperimento foi desenvolvidono Laboratório de Patologia da Madeira, da Coordenação de Pesquisas emProdutos Florestais (CPPF), do Instituto Nacional de Pesquisas da Amazônia (INPA), Manaus, AM.

Foi utilizada uma linhagem de L. strigosus, de ocorrência na Amazônia, a qual foi obtida da Coleção de Micro-organismos de Interesse Agrossilvicultural, do Laboratório de Patologia da CPPF/INPA. Originalmente, tal linhagem foi coletada na Estrada AM 240, km 10 (Estrada de Balbina, AM), no dia 11 de julho de 2005, sendo posteriormente identificada pelo Dr. José Luiz Bezerra e depositada na Coleção, em tubos de ensaio contendo meio de cultura BDA, com registro $\mathrm{N}^{\circ} .1466$.

Os meios de cultura foram preparados utilizando-se, em base seca, $100 \mathrm{~g}$ de substrato/ L final de infusão. Para isso foram necessários, em base seca: $80 \%$ de serragem (marupá, pau de balsa, estipe de pupunheira ou bagaço de cana-de-açúcar), 18\% de farelo de cereais (mistura de arroz, trigo e milho, na proporção 60: 20: 20) e $2 \%$ de $\mathrm{CaCO}_{3^{\prime}}$ para ajuste do $\mathrm{pH}(6,5)$. Assim, os meios de cultura foram preparados a partir da infusão de cada substrato em 1,5 L de água fervente durante 30 minutos. Em seguida, foram filtrados em algodão e o volume foi completado para $1 \mathrm{~L}$, sendo adicionados a cada meio $12 \mathrm{~g}$ de dextrose e $15 \mathrm{~g}$ de ágar/L. Os diferentes meios foram autoclavados a $121^{\circ} \mathrm{C}$ e vertidos em placas de Petri em câmara de fluxo laminar.

Os meios de cultura receberam uma codificação de acordo com cada resíduo testado: serragem de marupá (MA), serragem de pau de balsa (BA), estipe da pupunheira (PU) e bagaço de cana-de-açúcar (BC). O meio malte (ME) foi utilizado como testemunha, uma vez que comumente é utilizado no cultivo in vitro de fungos.

Discos de $9 \mathrm{~mm}$ de diâmetro de matriz secundária da linhagem de L. strigosus (cultivadas em placas de Petri contendo meio malte) foram depositados sobre os meios previamente preparados, compondo os tratamentos do presente experimento. As placas foram distribuídas inteiramente ao acaso e mantidas em estufas incubadoras ajustadas para 20, 25, 30, 35, 40,45 e $50^{\circ} \mathrm{C}$. Neste período, a cada 24 horas, foram realizadas medições do crescimento radial do L. strigosus através de duas medições equidistantes entre si, até o momento em que em um dos tratamentos a colônia fúngica atingisse a proximidade das bordas da placa de Petri.

O delineamento experimental utilizado foi inteiramente casualizado, em esquema fatorial $5 \times 7$, cujos tratamentos corresponderam às combinações dos cinco meios de cultura com as sete condições de temperatura, tendo no total 35 tratamentos. Cada tratamento foi composto por quatro repetições, sendo cada repetição correspondente a uma placa de Petri, totalizando 140 placas. Os dados foram submetidos à análise de variância e as médias foram comparadas pelo teste de Tukey (5\%) (SNEDECOR; COCHRAN, 1972).

Houve interação positiva entre os meios de cultura e as temperaturas de incubação (Tabela 1). As médias de crescimento micelial mais satisfatórias ocorreram quando submetidas à temperatura de $35^{\circ} \mathrm{C}$, pois nesta temperatura não houve diferença significativa do crescimento micelial do L. strigosus entre os diferentes meios de cultura testados. Este resultado está de acordo com VARGAS-ISLA; ISHIKAWA (2008) que, avaliando as condições ótimas do crescimento micelial in vitro de uma linhagem de $L$. strigosus isolada da Amazônia brasileira, verificaram que, dentre as temperaturas testadas $(25,30,35,40 \mathrm{e}$ $45^{\circ} \mathrm{C}$ ), a temperatura mais favorável foi a de $35^{\circ} \mathrm{C}$.

Um dos mais importantes fatores que influenciam o crescimento micelial dos fungos é a temperatura. Sobre isso, Lechner; Albertó (2007), testando a temperatura ótima para o crescimento micelial de linhagens de ocorrência natural de Lentinus tigrinus, observaram que a temperatura de $30^{\circ} \mathrm{C}$ foi a mais favorável. GBOLAGADE et al. (2006), avaliando o crescimento micelial Lentinus subnudus em meios semissintéticos, verificaram que o melhor crescimento foi obtido a $30^{\circ}$ C. AKINYele; Adetuyi (2005) estudaram o efeito de diferentes resíduos, $\mathrm{pH}$ e temperaturas no crescimento micelial de Volvariella volvacea e verificaram que a temperatura de $30^{\circ} \mathrm{C}$ foi a mais favorável. No cultivo de uma linhagem de Pleurotus ostreatus, de ocorrência na Amazônia, em meio à base de serragem da espécie madeireira Simarouba amara, SALES-CAMPOS et al. (2008) testaram cinco temperaturas de incubação $\left(22,25,27,30\right.$ e $35^{\circ}$ C) e verificaram que a de $25^{\circ} \mathrm{C}$ foi a mais indicada para o crescimento micelial.

Os dados referentes ao crescimento micelial das linhagens de L. strigosus foram ajustados a um modelo quadrático (Fig. 1). Verifica-se que a temperatura de $35^{\circ} \mathrm{C}$ foi a mais promissora, uma vez que foi a única temperatura em que o micélio fúngico atingiu o seu máximo crescimento, em todos os meios de cultura, após 5 dias de incubação. Esses resultados estão de 
acordo com Мотато et al. (2006) que, avaliando o desenvolvimento de Pleurotus djamor em resíduos agroindustriais, verificaram uma evidente influência da temperatura sobre o crescimento micelial, onde os diferentes substratos de Musa paradisiaca e Cariniana pyriformis mostram uma menor velocidade de crescimento quando submetida a uma temperatura de $15^{\circ} \mathrm{C}$. Já as temperaturas de 20 e $26^{\circ} \mathrm{C}$ favorecem o crescimento do fungo, e acima de $26^{\circ} \mathrm{C}$ observou-se os melhores resultados.
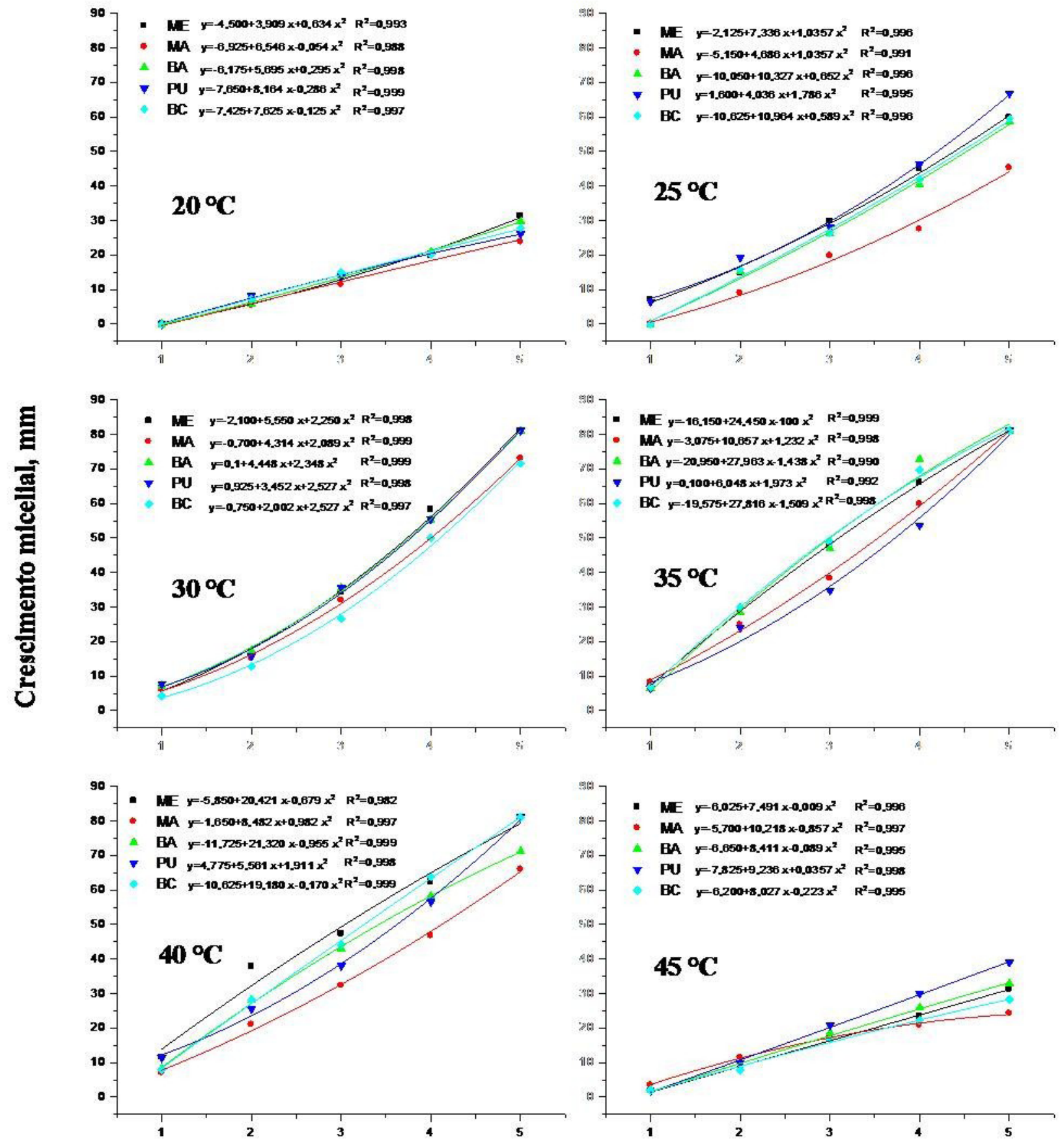

\section{Tempo de incubação, dias}

Fig. 1 - Crescimento micelial de Lentinus strigosus em cinco meis de cultura à base de malte (ME), serragem de marupá (MA), serragem de pau de balsa (BA), estipe de pupunheira (PU) e bagaço de cana-de-açúcar (BC), em diferentes temperaturas. OBS: não houve crescimento do L. strigosus a $50^{\circ} \mathrm{C}$, em nenhum dos meios de cultura testados. 
Em relação ao meio de cultura, verificou-se que para $20^{\circ} \mathrm{C}$ as maiores médias de crescimento micelial do L. strigosus ocorreram nos meios PU, ME, BA e $\mathrm{BC}$; para $25^{\circ} \mathrm{C} \mathrm{e} 40^{\circ} \mathrm{C}$ os melhores resultados foram proporcionados pelos meios $\mathrm{PU}, \mathrm{ME}$, e $\mathrm{BC}$; para $30^{\circ} \mathrm{C}$ foram PU, ME e BA; para $35^{\circ} \mathrm{C}$ não houve diferenças de crescimento micelial entre os meios testados; para $45^{\circ} \mathrm{C}$ os melhores resultados foram observados em PU e BA (Tabela 1). Assim, de uma forma geral, o meio PU éo mais recomendado, já que foi o único meio de cultivo que obteve as maiores médias de crescimento em todas as temperaturas testadas (com exceção a temperatura de $50^{\circ} \mathrm{C}$, a qual não possibilitou o crescimento do L. strigosus em nenhum dos meios de cultura). Este resultado está de acordo com Bilay et al. (2000) que, ao avaliarem o crescimento de trinta espécies de cogumelos comestíveis em diferentes meios de cultura, concluíram que o crescimento micelial destas espécies estudadas é diferente e depende do tipo de meio de cultivo utilizado e do $\mathrm{pH}$.

As diferenças de crescimento micelial de cogumelos comestíveis em diferentes substratos já foram relatadas em muitos trabalhos (NYOCHEMBENG et al.,
2008; ANDRADE et al., 2007; ANDRADE; GRACIOLLI, 2005; BOYLE, 1998; MAKI et al., 2001). ANDRADE et al. (2008), avaliando o crescimento micelial das linhagens LE-95/01 e LE-96/18 de L. edodes em dez diferentes meios de cultura à base de serragem de eucalipto, verificaram que o meio de cultura à base de extrato de serragem de Eucalyptus citriodora foi o mais promissor. PHILIPPOussis et al. (2003) demonstraram que a taxa de crescimento micelial está relacionada com a biodisponibilidade de nitrogênio do substrato de cultivo e GBOLAGADE et al. (2006) relataram que cada fungo utiliza uma relação $\mathrm{C} / \mathrm{N}$ específica.

Um rápido crescimento micelial é importante, uma vez que reduz os índices de contaminações. Sobre isso, JonATHAN et al. (2008) verificaram que uma rápida colonização micelial do Pleurotus tuber-regium, nos seletivos substratos, tais como resíduos de madeira de Holoptelia grandis e Milicia excelsa, reduz consideravelmente o crescimento de outros organismos competidores.

Portanto, a temperatura de $35^{\circ} \mathrm{C}$ foi a mais favorável para o crescimento micelial de Lentinus strigosus e o meio à base de estipe de pupunheira foi o mais promissor para o cultivo deste fungo.

Tabela 1 - Crescimento micelial (mm) in vitro de uma linhagem de Lentinus strigosus de ocorrência na Amazônia em meios de cultura à base de malte (ME), serragem de marupá (MA), serragem de pau de balsa (BA), estipe de pupunheira (PU) e bagaço de cana-de-açúcar (BC), em diferentes temperaturas, após cinco dias de desenvolvimento.

\begin{tabular}{lcccccc}
\hline & \multicolumn{5}{c}{ Meios de cultura } \\
\cline { 2 - 6 } Temperaturas & ME & MA & BA & PU & BC \\
\hline $20^{\circ} \mathrm{C}$ & $31,5 \mathrm{C}$ a & $24,0 \mathrm{D} \mathrm{b}$ & $30,0 \mathrm{D} \mathrm{ab}$ & $26,5 \mathrm{D} \mathrm{ab}$ & $28,0 \mathrm{D} \mathrm{ab}$ \\
$25^{\circ} \mathrm{C}$ & $60 \mathrm{~B} \mathrm{ab}$ & $45,5 \mathrm{C} \mathrm{C}$ & $58,8 \mathrm{C} \mathrm{b}$ & $67,0 \mathrm{~B} \mathrm{a}$ & $60,0 \mathrm{C} \mathrm{ab}$ \\
$30^{\circ} \mathrm{C}$ & $81 \mathrm{~A} \mathrm{a}$ & $73,3 \mathrm{~B} \mathrm{~b}$ & $81,0 \mathrm{~A} \mathrm{a}$ & $81,0 \mathrm{~A} \mathrm{a}$ & $71,5 \mathrm{~B} \mathrm{~b}$ \\
$35^{\circ} \mathrm{C}$ & $81 \mathrm{~A} \mathrm{a}$ & $81,0 \mathrm{~A} \mathrm{a}$ & $81,0 \mathrm{~A} \mathrm{a}$ & $81,0 \mathrm{~A} \mathrm{a}$ & $81,0 \mathrm{~A} \mathrm{a}$ \\
$40^{\circ} \mathrm{C}$ & $81 \mathrm{~A} \mathrm{a}$ & $66,5 \mathrm{~B} \mathrm{~b}$ & $71,3 \mathrm{~B} \mathrm{~b}$ & $81,0 \mathrm{~A} \mathrm{a}$ & $81,0 \mathrm{~A} \mathrm{a}$ \\
$45^{\circ} \mathrm{C}$ & $31,5 \mathrm{Cbc}$ & $24,5 \mathrm{D} \mathrm{c}$ & $33,3 \mathrm{D} \mathrm{ab}$ & $39,5 \mathrm{C} \mathrm{a}$ & $28,5 \mathrm{D} \mathrm{bc}$ \\
$50^{\circ} \mathrm{C}$ & $0,0 \mathrm{Da}$ & $0,0 \mathrm{E} \mathrm{a}$ & $0,0 \mathrm{E} \mathrm{a}$ & $0,0 \mathrm{E} \mathrm{a}$ & $0,0 \mathrm{E} \mathrm{a}$ \\
\hline
\end{tabular}

Médias seguidas de letras maiúsculas nas colunas não diferem entre si (Tukey, 5\%).

Médias seguidas de letras distintas, minúscula na linha e maiúscula na coluna, diferem entre si pelo teste de Tukey $(\mathrm{p}<0,05)$. CV $(\%)=7,21$. 


\section{AGRADECIMENTO}

Ao Dr. José Luiz Bezerra pela identificação do fungo estudado nesta pesquisa.

Ao MCT/CNPQ/INPA/CT-Amazônia/CTEnergia pelo apoio financeiro.

\section{REFERÊNCIAS}

AKINYELE, B.J.; ADETUYI, F.C. Effect of agrowastes, $\mathrm{pH}$ and temperature variation on the growth of Volvariella volvacea. African Journal of Biotechnology, v.4, n.12, p.1390-1395, 2005.

ANDRADE, M.C.N.; GRACIOLLI, L.A. Controle de fungos contaminantes no cultivo do cogumelo comestível shiitake em toros de eucalipto. Acta Scientarium. Agronomy, v.27, n.2, p.293-299, 2005.

ANDRADE, M.C.N.; CALONEGO, F.W.; MINHONI, M.T.A.; SEVERO, E.T.D.; KOPYTOWSKI FILHO, J. Avaliação do crescimento micelial de linhagens de shiitake, da produção em toras de eucalipto e de alterações físicas da madeira. Acta Scientarium. Agronomy, v.29, n.1, p.23-27, 2007.

ANDRADE, M.C.N.; SILVA, J.H.; MINHONI, M.T.A.; ZIED, D.C. Mycelial growth of two Lentinula edodes strains in culture media prepared with sawdust extracts from seven eucalyptus species and three eucalyptus clones. Acta Scientiarum. Agronomy, v.30, n.3, p.333-337, 2008.

BILAY, V.T.; SOLOMKO, E.F.; BUCHALO, A.S. Growth of edible and medicinal mushrooms on commercial agar media. In: VAN GRIENSVEN, L.J.L.D. (Ed.). Science and cultivation of edible fungi. Rotterdam: Balkema, 2000. v.2, p.779-782.

BONONI, V.L.; CAPELARI, M.; MAZIEIRO, R.; TRUFEM, S.F.B. Cultivo de cogumelos comestíveis. São Paulo: Ícone, 1999. 206p.

BOYLE, C.D. Nutritional factors limiting the growth of Lentinula edodes and other white-rot fungi in wood. Soil Biology Biochemistry, v.30, n.6, p.817-823, 1998.

DONINI, L.P.; BERNARDI, E.; MINOTTO, E.; NASCIMENTO, J.S. Desenvolvimento in vitro de Pleurotus spp. sob a influência de diferentes substratos e dextrose. Arquivos do Instituto Biológico, São Paulo, v.72, n.3, p.331-338, 2005.

GBOLAGADE, J.S.; FASID, I.O.; AJAYI, E.J.; SOBOWALE, A.A. Effect of physico-chemical factors and semi-synthetic media on vegetative of Lentinus subnudus (Berk.), and edible mushroom from Nigeria. Food Chemistry, v.99, p.742-747, 2006.

HATVANI, N. Antibacterial effect of the culture fluid of Lentinula edodes mycelium grown in submerged li- quid culture. International Journal of Antimicrobial Agents. v.17, n.1, p.71-74, 2001.

JONATHAN, S.G.; FASIDI, I.O.; AJAYI, A.O.; ADEGEYE, O. Biodegradation of Nigerian wood wastes by Pleurotus tuber-regium (Fries) Singer. Bioresource Technology, v.99, p.807-811, 2008.

LECHNER, B.E.; ALBERTÓ, E. Optimal conditions for the fruit body production of natural occurring strains of Lentins tigrinus. Bioresource Technology, v.98, p.18661869, 2007.

MAKI, C.S.; TEIXEIRA, F.F.; PAIVA, E.; PACCOLAMEIRELLES, L.D. Analyses of genetic variability in Lentinula edodes through mycelia responses to different abiotic conditions and RAPD molecular markers. Brazilian Journal of Microbiology, v.32, n.3 p.170-175, 2001.

MONTINI, R.M.C.; PASSOS, J.R.S.; EIRA, A.F. Digital monitoring of mycelium growth kinetics and vigor of shiitake (Lentinula edodes (Berk.) Pegler) on agar medium. Brazilian Journal of Microbiology, v.37, p.90-95, 2006.

MOTATO, K.E.; MEJÍA, A.; LEÓN, A. Evaluación de los residuos agroindustriales de plátano (Musa paradisíaca) y aserrín de abarco (Cariniana piriformes) como sustratos para el cultivo del hongo Pleurotus djamor. Vitae, v.13, n.1, p.24-29, 2006.

NYOCHEMBENG, L.M.; BEYL, C.A.; PACUMBABA, R.P. Optimizing edible fungal growth and biodegradation of inedible crop residues using various cropping methods. Bioresource Technology, v.99, p.5645-5649, 2008.

PHILIPPOUSSIS, A.; DIAMANTOPOULOU, P.; ZERVAKIS, G. Correlation of the properties of several lignocellulosic substrates to the crop performance of the shiitake mushroom Lentinus edodes. World Journal of Microbiology and Biotechnology, v.19, n.6, p.551-557, 2003.

SALES-CAMPOS, C.; EIRA, A.F.; JESUS, M.A.; CAMPAGNOLLI, F.; ANDRADE, M.C.N. Crescimento micelial de Pleurotus ostreatus em resíduo de Simarouba amara. Pesquisa Agropecuária Brasileira, v. 43, n. 11, p. 1633-1635, 2008.

SILVA, E.M.; MACHUCA, A.; MILAGRES, A.M. Effect of cereal brans on Lentinula edodes growth and enzyme acticities during cultivation on forestry waste. Letter in Applied Microbiology, v.40, n.4, p.283-288, 2005.

SNEDECOR, G.W.E.; COCHRAN, W.G. Statiscal methods. 6.ed. Ames: Iwoa State University Press, 1972. 325p.

VARGAS-ISLA, R.; ISHIKAWA, N.K. Optimal conditions of in vitro mycelial growth of Lentinus strigosus, an edible mushroom isolated in the Brazilian Amazon. Mycoscience, v.49, p.215-219, 2008.

Recebido em 2/12/09

Aceito em 15/7/10 